\title{
A FAMILIAL TUBULAR ABSORPTION DEFECT OF GLUCOSE AND AMINO-ACIDS
}

\author{
BY \\ JOSEPH LUDER and WILFRID SHELDON \\ From The Hospital for Sick Children, Great Ormond Street, London
}

(RECEIVED FOR PUBLICATION SEPTEMBER 14, 1954)

It has become increasingly clear in recent years that a group of disorders in childhood results from defects in reabsorption by the renal tubules. The common feature of these conditions is a failure to reabsorb adequately a number of substances which are filtered out of the blood by the glomeruli and which are present in the blood in normal concentrations. The substances include water, glucose, amino-acids, phosphate, chloride, bicarbonate, sodium and potassium ions.

While it is evident that many of these reabsorption defects may be acquired in the course of renal disease, a growing number of conditions have been described in which these appear in early childhood. Many are probably congenital. They are strikingly selective, and exhibit in most cases a strong familial tendency.

The best known of these conditions is renal glycosuria, in which a selective leak of glucose exists, transmitted as a Mendelian dominant gene. This is a benign and symptomless condition, which probably explains why it is frequently not discovered until adult life. Its occurrence in childhood and even in infancy is, however, well documented (Shafton and Poncher, 1934). A failure to reabsorb water gives rise to the condition variously termed 'nephrogenic diabetes insipidus' (Williams, 1946) or 'pitressinresistant diabetes insipidus' (Dancis, Birmingham and Leslie, 1948), in which severe polyuria, polydypsia and dehydration fever are present from birth and soon become clinically evident. This condition also is familial (Williams, 1946), although its rarity has so far prevented more exact knowledge of the nature of the inheritance. Infantile renal acidosis is another example in which the reabsorption of basic and bicarbonate ions is impaired.

A tubular disturbance resulting in excessive loss of sodium and chloride ions sometimes develops in cases of chronic nephritis. This condition, 'saltlosing nephritis', was first described by Thorn, Koepf and Clinton (1944), and has so far been seen only in adults. It is tempting to speculate that it will one day be discovered in childhood as a congenital tubular disturbance, causing dehydration and inanition.

This paper is concerned particularly with failure of glucose, phosphate, and amino-acid reabsorption. These abnormalities are frequently associated with each other, perhaps because all these substances are reabsorbed in the proximal tubule (Richards, 1938; Stowers and Dent, 1947). A family is presented in which the reabsorption of glucose and amino-acids was interfered with, but not that of phosphate. No previous report has appeared of this combination of disturbances, which came to light because of moderate dwarfism in one of the patients.

\section{Case Histories}

Case 1. Lindsay B., aged 5 , one of female twins, was brought for advice because of poor appetite, thirst and failure to grow. She had been miserable for the previous few months, and was sleeping badly.

She was the smaller twin at birth, having a birth weight of $4 \mathrm{lb}$. $15 \mathrm{oz}$., but apart from a slower growth and weight gain than her twin her early history was uneventful. There were no previous illnesses. The parents were both well and of normal height and appearance, but there was a history that the paternal grandfather had died of an illness resembling diabetic coma after having been found in earlier years to have sugar in the urine.

On examination the patient was a considerably stunted, sallow and underweight child, who might have passed on appearance for a case of renal rickets except that she was vivacious and active, and showed neither knock-knee nor other skeletal deformities. Her height was 36 in. and weight $23 \mathrm{lb} .14 \mathrm{oz}$. Her intelligence was normal and no abnormalities were found in any system, including the genitalia and skeleton. In particular, there were no signs of rickets.

Blood analysis gave: Urea $29 \mathrm{mg} . \%$, calcium 10.1 mg. $\%$, phosphorus $4.2 \mathrm{mg}$. $\%$, bicarbonate $45.0 \mathrm{vol}$. $\mathrm{CO}_{2} \%$, chlorides $623 \mathrm{mg} . \%$ as $\mathrm{NaCl}$, potassium 17 mg. $\%$, sodium $345 \mathrm{mg} . \%$, alkaline phosphatase 31.9 units $\%$ (King-Armstrong), sugar $73 \mathrm{mg} . \%$, and $\mathrm{pH} 7 \cdot 2$ (at $37^{\circ} \mathrm{C}$.).

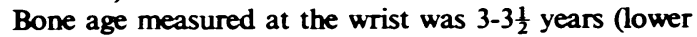
limits of normal). 
The urine was examined by paper chromatography and contained a small quantity of protein, glucose 0.5 $2 \mathrm{~g}$. \%, fructose $25 \mathrm{mg}$. \% and a gross excess of aminoacids. Proline, leucine and valine were most prominent, and cystine, lysine, tyrosine, serine, threonine, alanine, glutamine, beta-alanine, alpha-amino-butyric acid and methionine were also greatly in excess.

A glucose tolerance curve was normal.

Case 2. At this stage, the twin, Glenys, was admitted. This child had had no symptom or previous illnesses. Her birth weight was $5 \mathrm{lb}$. $15 \mathrm{oz}$. and she had always thrived rather better than her twin.

On examination she was a sturdy, cheerful child, somewhat taller and heavier than her twin. Her weight (32 lb.) was rather low for her age, but her height (403 in.) was within normal limits. No abnormal physical signs were found in any system.

Blood analysis gave: Urea $30 \mathrm{mg}$. \%, calcium 10.2 mg. $\%$, phosphorus $5 \mathrm{mg}$. $\%$, bicarbonate 51.4 vol. $\mathrm{CO}_{2} \%$, chloride $608 \mathrm{mg} . \%$ as $\mathrm{NaCl}$, potassium 16.4 mg. $\%$, sodium $330 \mathrm{mg}$. $\%$, alkaline phosphatase $27 \cdot 2$ units \% (King-Armstrong), sugar $82 \mathrm{mg}$. $\%$ and $\mathrm{pH}$ $7 \cdot 2$ (at $37^{\circ} \mathrm{C}$.).

The urine showed traces of protein, but was otherwise normal.

A glucose tolerance curve was normal.

The urine was examined by paper chromatography and showed considerable excess of the same amino-acids as in the twin, and of glucose and fructose. All these substances were present in rather smaller amounts than in the twin. Some protein was also present.

Both Twins. Bone marrow smears showed no cystine crystals, nor were any seen on slit-lamp examination of the corneae.

Paper chromatography of blood showed that blood amino-acid levels were below normal, but the distribution patterns were normal.

Urinary nitrogen excretion was as follows:

\begin{tabular}{|c|c|c|c|c|}
\hline Excretion (in $24 \mathrm{~h}$ & & & Glenys & Lindsay \\
\hline $\begin{array}{l}\text { Total urinary nitrogen } \\
\text { Urea nitrogen } \\
\text { Ammonia nitrogen } \\
\text { Amino-acid nitrogen }\end{array}$ & $\begin{array}{l}\cdots \\
\cdots \\
\cdots\end{array}$ & $\begin{array}{l}\cdots \\
\cdots \\
\cdots\end{array}$ & $\begin{array}{ll}5 \cdot 64 \mathrm{~g} . \\
4 \cdot 86 & \mathrm{~g} . \\
252 & \mathrm{mg} . \\
396 & \mathrm{mg} .\end{array}$ & 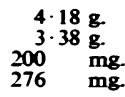 \\
\hline
\end{tabular}

The blood groups of the members of the family were as follows:

Twins OFV CDe/cde Ns Ns P-Lu-K - Le - Leb- Fy Mother OIV CDE/cde Ms Ns P- Lu - K - Le - Leb- Fy' Father OIV CDe/cde Ms Ns P- Lu - K - Lew - Leb - Fy" -

Parents. The mother showed no biochemical abnormalities in the blood or urine.

The father was a tall, well built man who looked and felt well, and was symptomless. His previous history contained nothing relevant. Apart from his father, his family history was also negative.

His urine contained an excess of glucose, fructose and amino-acids, in the same patterns as in the twins, but in rather smaller concentrations than in either of them. His blood amino-acid levels were below normal, but the distribution pattern was normal. His blood sugar, calcium, phosphorus and alkaline phosphatase levels were normal.

Patermal Grandfather. He was a very short, spare man, weighing about 7 stones. He was discovered in the late thirties to have glycosuria, which was investigated and found to be of renal type due to a low threshold. In his later years he suffered from intercostal neuralgia and arthritis of thoracic vertebrae 5-12. These vertebrae were osteoporotic and a diagnosis of Paget's disease was considered at one time. In 1945, at the age of 56, he complained of severe weakness after an emotional shock, and the discovery of sugar in the urine led to treatment by a diet which rendered his urine sugar-free. Ketosis developed and he died in coma.

\section{Discussion}

The presence of considerable amounts of glucose and amino-acids in the urine can be due only to a spill-over resulting from the failure of the renal tubules to reabsorb these substances entirely from the glomerular filtrate. When the renal tubules are functioning normally this can only occur when the glomerular filtrate concentrations of these substances rise above a certain critical level, that is, when the threshold of each is exceeded, but functional abnormalities of the tubules are found in which reabsorption fails in the presence of normal or even low glomerular filtrate concentrations. The thresholds in these cases are low. The normal blood glucose levels and tolerance curves, and the low blood amino-acid levels in our cases place them in the group of functional tubular failure causing low thresholds.

It is probable that normal tubular function is dependent on many influences. Harrison and Harrison (1941) showed that one of these influences is vitamin D. Deficiency of this vitamin, among other effects, diminishes the reabsorption of phosphate ions in the proximal tubule, resulting in phosphate leaking and low blood levels. This dysfunction is temporary, and is fully corrected by giving vitamin $D$. Glucose and amino-acids can be similarly affected in certain circumstances. Aminoaciduria in vitamin-deficiency rickets was reported by Jonxis, Huisman and Smith (1952). Vitamin D treatment greatly reduced but did not entirely abolish this amino-aciduria, and, in a later paper, Jonxis and Huisman (1953) reported that traces persisted in the urine of these patients. Since their report we have obtained similar findings in a case of vitamin-deficiency rickets.

Vitamin D deficiency rarely appears to upset 
glucose reabsorption in children, but glycosuria is well recognized in adult osteomalacia (Albright and Reifenstein, 1948). Vitamin C was shown by Jonxis and Wadman (1950) to act in a similar way on the renal tubules, and a deficiency will aggravate the amino-aciduria of vitamin-deficiency rickets.

In addition, it has been shown that a number of substances can act as poisons to the renal tubules, producing glycosuria and amino-aciduria. These manifestations are well known in lead poisoning in man (Wilson, Thomson and Dent, 1953), and Spencer and Franglen (1952) found them in lysol poisoning. Animals poisoned experimentally with uranium also produce glycosuria and aminoaciduria (Voegtlin and Hodge, 1949-53), and it is probable therefore that a number of substances can act in this way.

The exact mechanism of the congenital and hereditary variety of this tubular disturbance is not known. Stowers and Dent (1947), reporting the pathological findings in a fatal adult case of the Fanconi syndrome, state that phosphatase was present in Henle's loops and the collecting tubules, but absent from the proximal tubules, the exact reverse of the normal position. Jackson and Linder (1953) suggest that this deficiency may be the primary cause of the failure of reabsorption, as glucose and amino-acids are normally phosphorylated before absorption. This would not, however, explain how the defect might involve any one of these substances, unless it be that there are separate phosphatases for each. It is held by Fanconi (1954) that a deficiency of carbonic anhydrase in the proximal tubule may be one of the possible mechanisms underlying infantile renal acidosis, by causing an insufficient release of hydrogen ions from bicarbonate, and it may be that many, if not all, congenital tubular dysfunctions result from enzyme deficiency or inefficiency.

The pathology of these conditions has naturally been studied extensively only in the more severe and rapidly fatal variations, particularly the Fanconi syndrome. Severe degenerative changes have been found consistently in the renal tubular epithelium, the changes being more marked in the proximal than in other parts of the tubule (McCune, Mason and Clarke, 1943; Stowers and Dent, 1947). These changes may consist of flattening or swelling of the epithelium, fatty deposits in the basal stratum, deposits of particulate matter, possibly cystine, in the tubule cells, or fibrosis. Darmady (quoted by Fanconi, 1954) has demonstrated cellular atrophy in the proximal tubules of cases of tubular insufficiency by dissection of individual nephrons. Stowers and Dent conclude that the various changes represent different stages of one process. The question of glomerular lesions in this group of conditions is more doubtful. The constant small amounts of protein in the urine of our cases suggests the possibility of such lesions, although the normal blood urea and phosphorus levels do not indicate any great severity. Slight albuminuria could also be explained by secretion from abnormal tubules. Assuming that our cases had their renal abnormalities from birth, the survival of the grandfather till the age of 56 and the good general health and normal blood chemistry of the father do not argue for glomerular lesions of any consequence. The cause of death of the grandfather, from the information available, suggests ketotic coma, possibly as a result of severe carbohydrate restriction, rather than renal failure. It is also noteworthy that many cases of the Fanconi syndrome survive to adult life. King and Lochridge (1951) found normal glomeruli in their case, and Stowers and Dent (1947) found only minor changes. It appears from a study of the literature that severe glomerular lesions occur most often in cases with multiple reabsorptive defects associated with cystinosis, and in only a proportion of these.

The proximal tubule reabsorbs glucose, aminoacids, most of the phosphate ions, water, sodium and chloride ions (Fanconi, Ruegg and Dieterle, 1951).

Considering the first three substances only, it will be seen that there are seven possible variations of reabsorptive deficiencies, as follows: (1) Glucose, (2) phosphate, (3) amino-acids, (4) glucose and phosphate, (5) phosphate and amino-acids, (6) glucose and amino-acids, (7) glucose, phosphate and amino-acids.

Of these, (1) is the well recognized condition of renal glycosuria; (2) is vitamin-resistant hypophosphataemic rickets; (3) occurs in a selective form in hereditary cystinuria (Dent and Rose, 1951), a condition in which cystine, lysine and arginine fail to be reabsorbed but a general amino-acid leak has not been reported in the absence of glucose or phosphate leak; (4) is a combination of glycosuria and hypophosphataemic rickets, and has been reported in a number of cases in the literature quoted by McCune et al. (1943); (5) is a rare combination but occurred in one of the cases reported by Jonxis and Huisman (1953). In a number of cases of rickets showing amino-aciduria, one was found to be of the vitamin-resistant hypophosphataemic type. Variant (7) occurs together with other features, such as potassium leak and cystinosis, in the Fanconi syndrome.

Variant (6) occurred in the family reported in this paper. The development of rickets in this type of 
tubular disturbance appears to depend on whether phosphate leaks. No evidence of rickets could be found either radiologically or clinically in the twins, although the serum alkaline phosphatase levels were considerably raised in both. No certain explanation can be given for this finding at present. The possibility exists that the cause might lie in a disturbance of liver function. The work of Himsworth and Glynn (1944) has shown that a deficiency of cystine and methionine in the diet will lead to liver cirrhosis in rats. Hepatic lesions, comprising fatty infiltration, centrilobular necrosis and frank cirrhosis, occur in a high proportion of cases of the Fanconi syndrome (McCune et al., 1943). The case reported by Stowers and Dent (1947) had gross cirrhosis, and several discrete areas of malignant hepatoma. It seems likely, therefore, that a persistent loss of methionine and cystine in the urine, leading to low blood levels, has the same effect as a deficiency of these amino-acids in the diet, but this cannot be regarded as the whole explanation of the hepatic lesions until further work has shown a close coincidence between those cases which lose methionine and cystine in the urine and those which have hepatic lesions. Methionine and cystine were passed in considerable excess in the urine of the twins, but for the present this explanation for the raised alkaline phosphatase levels is speculative.

It is interesting to consider the reason why one twin failed to grow as well as the other. A simple explanation would be that the twins were binovular, and this cannot be ruled out with absolute certainty. They do, however, bear a close facial resemblance (Fig. 1), and have identical ABO blood groups, rhesus genotypes and other associated cell factors. Having regard to the blood groups of the parents, the probability of their being identical twins can be stated as $64: 1$.

Quantitative estimations of the amino-acid nitrogen excretion in the urine show that the total output per 24 hours is of the order of $7 \%$ of the total daily nitrogen excretion, a figure which seems inadequate to cause any significant protein starvation. Were this amino-acid loss a causative factor, one would also expect the dwarfed twin to pass considerably more amino-acids than her sister, whereas she appears to pass approximately the same amount, or perhaps less. The chemical estimations must be regarded as being more accurate for quantitative purposes than the paper chromatography findings. An amino-acid nitrogen loss of $7 \%$ of the total nitrogen excretion is, however, quite abnormal. Bickel and his associates (1952) state that anything greater than $2 \%$ is pathological, and many of their cases had coefficients of over $10 \%$.

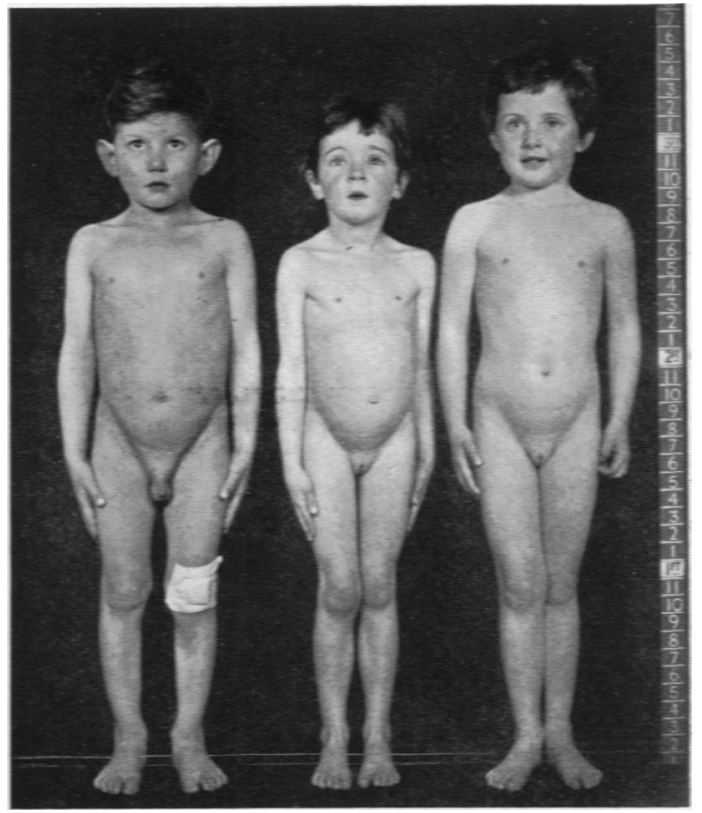

FiG. 1.-The twins with normal control.

If, however, the total amino-acid loss seems unlikely to account for dwarfism, it is possible that the loss of those regarded as essential may do so. Threonine, valine, leucine, lysine and methionine, all of which were found in the urine of our cases, come into this category. We have no proof, however, that these are being lost in greater quantities in the dwarfed child than in her sister.

It can only be said at this stage that the same gene has acted with different force in the three generations, and in the two presumably identical twins. This phenomenon is well known in cases of hereditary cystinuria and the Fanconi syndrome, and Stowers and Dent (1947) offer the suggestion that more than one gene is involved in this group of tubular dysfunctions and that the subsidiary genes may alter the manifestations of the main gene.

\section{Summary}

The congenital defects of renal tubular function are discussed, with particular reference to disturbances of glucose, phosphate and amino-acid reabsorption.

A family is presented in which a defect in glucose and amino-acid reabsorption was transmitted as a dominant gene to three successive generations, the youngest of which consisted of twins. This particular defect is one of seven possible combinations 
involving glucose, phosphate and amino-acids, and is likely to be symptom-free unless severe and persistent loss of essential amino-acids leads to stunting of growth.

Thanks are due to Dr. W. W. Payne for the biochemical estimations, to Dr. L. Woolf for the paper chromatography results, and to Drs. Brice Smith, A. A. MacNair and Francis Bach for clinical details of the grandfather.

\section{REFERENCES}

Albright, F. and Reifenstein, E. C. (1948). The Parathyroid Glands and Metabolic Bone Disease, p. 206. Baltimore.

Bickel, H., Baar, H. S., Astley, R., Douglas, A. A., Finch, E., Harris, H., Harvey, C. C., Hickmans, E. M., Philpott, M. G., Small wood, W. C., Smellie, J. M. and Teale, C. G. (1952). Acto wood, W. C., Smellie, J. M. and

Dancis, J., Birmingham, J. R. and Leslie, S. H. (1948). Amer. J. Dis. Child., 75, 316 .

Dent, C. E. and Rose, G. A. (1951). Quart. J. Med., n.s. 20, 205.
Fanconi, G. (1954). Archives of Disease in Childhood, 29, 1. , Rüegg, J. and Dieterk, E. (1951). Helv. paediat. Acta, 6, 281. Harrison, H. E. and Harrison, H. C. (1941). J. clin. Imvest., 20, 47.

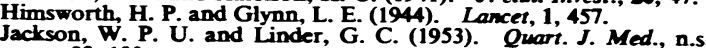
22. $\mathbf{P}$.

Jonxis, J. H. P. and Huisman, T. H. J. (1953). Lancet, 2, 428.

- - and Smith, P. A. (1952). Ibid., 2, 1015. and Wadman, S. K. (1950). Maandsch. Kindergeneesk., 18, 251.

King, F. P. and Lochridge, E. P. (1951). Amer. J. Dis. Child., 82. 446.

McCune, D. J., Mason, H. H. and Clarke, H. T. (1943). Ibid. 65,81

Richards, A. N. (1938). Proc. roy. Soc. B, 126, 398. Shafton, A. L. and Poncher, H. G. (1934). Amer. J. Dis. Child.,

Spencer, A. G. and Franglen, G. T. (1952). Lancet, 1, 190

Stowers, J. M. and Dent, C. E. (1947). Quart. J. Med., n.s. 16, 275.

Thorn, G. W., Koepf, G. F. and Clinton, M., Jr. (1944). New Engl. J. Med., 231, 76

Voegtlin, C. and Hodge, H. C. (1949-53). Pharmacology and Toxicology of Uranium Compounds. New York.

Williams, R. H. (1946). J. clin. Invest., 25, 937.

Wilson, V. K., Thomson, M. L. and Dent, C. E. (1953). Lancet, 2, 66 . 